\title{
Development of Mid Density Carbon Phenolic Ablators for Future Re-Entry Capsules
}

\author{
By Kenichi HiRAI, ${ }^{1)}$ Akiko NAKAZATo, ${ }^{1)}$ Jun KoyAnAgI, ${ }^{2)}$ and Kazuhiko YAMAdA ${ }^{3)}$ \\ ${ }^{1)}$ IHI Aerospace Co., Ltd., Tomioka, Japan \\ ${ }^{2)}$ Tokyo University of Science, Tokyo, Japan \\ ${ }^{3)}$ Institute of Space and Astronautical Science, JAXA, Sagamihara, Japan
}

(Received June 16th, 2017)

\begin{abstract}
Mid-density carbon phenolic (MD-CFRP) is a promising candidate for heat shield materials for future re-entry capsules because it could provide us with much lighter heat shields than the conventional high-density CFRP and also it could be possible to be free of delamination even if it was heated in the cross-ply direction, Here in this paper, we introduce our in-house R\&D activities on the MD-CFRP which is currently underway.
\end{abstract}

Key Words: Re-Entry Capsule, Ablator, Carbon Phenolic

$\begin{array}{cll}\text { Nomenclature } & \\ A & : & \text { cross sectional area } \\ B & : & \text { non-dimensional recession rate } \\ g & : & \text { mass transfer coefficient } \\ h & : & \text { enthalpy } \\ i & : & \text { thickness of char layer } \\ K & : & \text { permeability } \\ L & : & \text { thickness of a specimen } \\ m & : & \text { mass flux } \\ P & : & \text { pressure } \\ \dot{q} & : & \text { heat flux } \\ R & : & \text { recession rate } \\ V & : & \text { volume, volume fraction } \\ \dot{V} & : & \text { volume flow rate } \\ v & : & \text { velocity } \\ W & : & \text { weight, weight fraction } \\ x & : & \text { depth position in a specimen } \\ \Delta t & : & \text { heating duration time } \\ \mu & : & \text { viscosity } \\ \rho & : & \text { density } \\ \Phi_{b l o w} & : & \text { blocking effect }\end{array}$

Subscripts

$\begin{array}{lll}0 & : & \text { initial } \\ \mathrm{ab} & : & \text { oxidation reaction } \\ \mathrm{C} & : & \text { char layer } \\ \mathrm{CAL} & : & \text { calculated } \\ \text { cfrp } & : & \text { MD-CFRP } \\ \text { cloth } & : & \text { carbon cloth } \\ \text { conv } & : & \text { convection } \\ \mathrm{cW} & : & \text { cold wall } \\ \text { dry } & : & \text { dry condition } \\ \text { EXP } & : & \text { experimental }\end{array}$

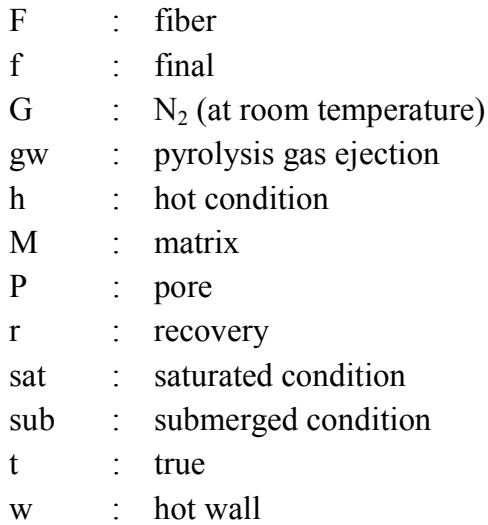

\section{Introduction}

The heat shield material used on the HAYABUSA-2 capsule which was successfully launched in 2015 is the same heritage high-density carbon phenolic (HD-CFRP) as the one on the HAYABUSA. Although currently it is one of the most reliable heat resistant materials, it has led to such heavy heat shield system with the mass fraction of heat shield exceeding $50 \%$ by weight as in HAYABUSA capsule as shown in Fig. 1, possibly due to its high density of $1.3 \mathrm{~g} / \mathrm{cm}^{3}$. However, when we look at the fairly good condition of the HAYABUSA heat shield after it was successfully recovered, we have an impression that the HD-CFRP maybe overkill and the material should be much lighter for the demanding future missions with tighter weight constraints, whose maximum convective heat flux levels are currently estimated less than $12 \mathrm{MW} / \mathrm{m}^{2}$, which is equivalent to the convective heat flux of the HAYABUSA. ${ }^{2)}$ As one example of the missions, the concept of a Jupiter Trojan Asteroids sample return mission is shown in Fig. 2.")

The mid-density carbon phenolic (MD-CFRP) comprises 
carbon cloth and phenolic resin, as is the case with conventional HD-CFRP. However, the phenolic resin matrix in the MD-CFRP intentionally contains well-controlled amount of voids, which makes the density of MD-CFRP lower and the gas permeability higher, leading to lower built-up pressure inside the ablator when heated and the much lower possibility of delamination.

Thus, MD-CFRP will be a promising candidate for heat shield materials for future re-entry capsules. We could enjoy the benefits of MD-CFRP by allowing for more payload weight and possibly by eliminating the need of demanding arc-jet experiments at overseas facilities.

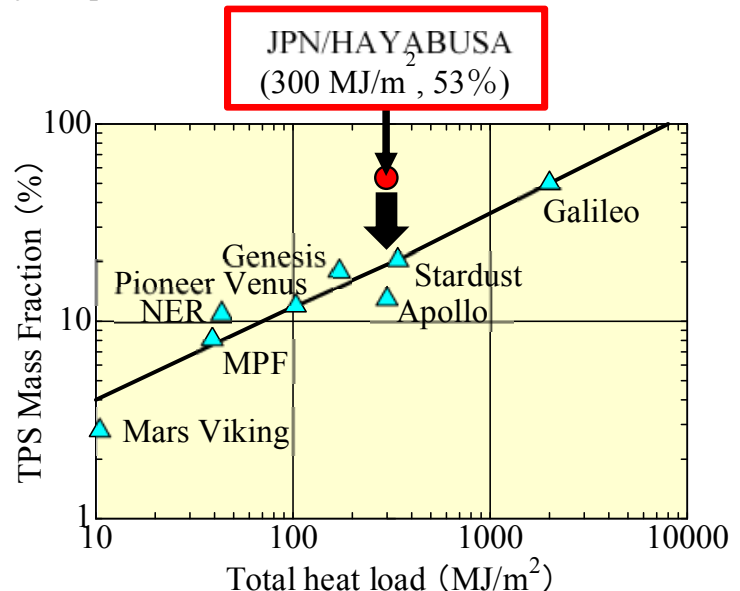

Fig. 1. The relationship between the TPS mass fraction and total heat load for various re-entry capsules. ${ }^{1)}$

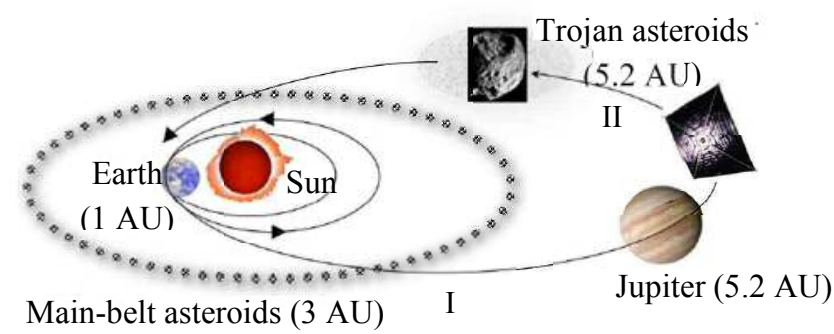

Fig. 2. The concept of a Jupiter Trojan Asteroids sample return mission. ${ }^{2)}$
The development of MD-CFRP is currently underway in our in-house R\&D activities. Here, in this paper, we introduce the status of the development.

\section{Preparation of MD-CFRP}

\subsection{Basic idea}

In HD-CFRP, both porosity and gas permeability increase with the advancement of the degree of pyrolysis reaction of the phenolic resin, as shown in Fig. 3. And our experiences show that the delamination generally occurs in the relatively low temperature region.

Therefore, in this research the porosity level for MD-CFRP at room temperature is targeted around $30 \%$ by volume.

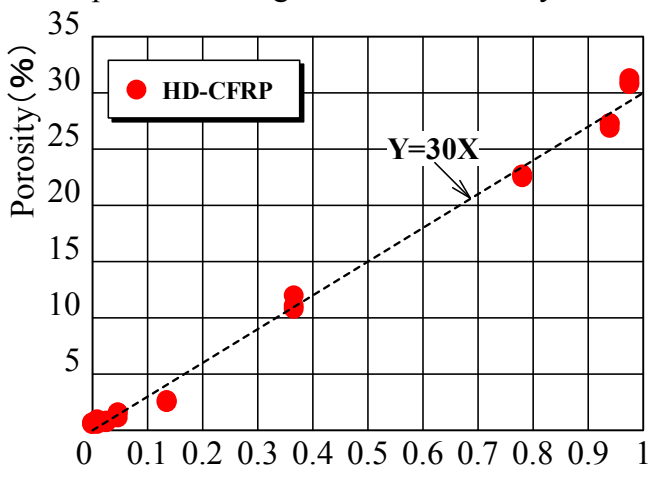

Degree of Pyrolysis Reaction (-)

Fig. 3. The relationship between porosity and degree of pyrolysis reaction for a HD-CFRP.

\subsection{Outline of the manufacturing process}

The manufacturing flow of the MD-CFRP is roughly shown in Fig. 4. We start with a Kynol 509 cloth (Gun Ei Chemical Industry, Japan). After carbonization of the cloths, they are impregnated with phenolic resin diluted with a solvent (in the present case, methanol), which make sheets of prepreg after drying process. At this stage, the prepreg contains some solvent. The number of layers which sheets of the prepreg are stacked is determined by the imposed pressure at room temperature depending on the requested VF (fiber volume fraction). Then, instead of imposing pressure, we use bolts to
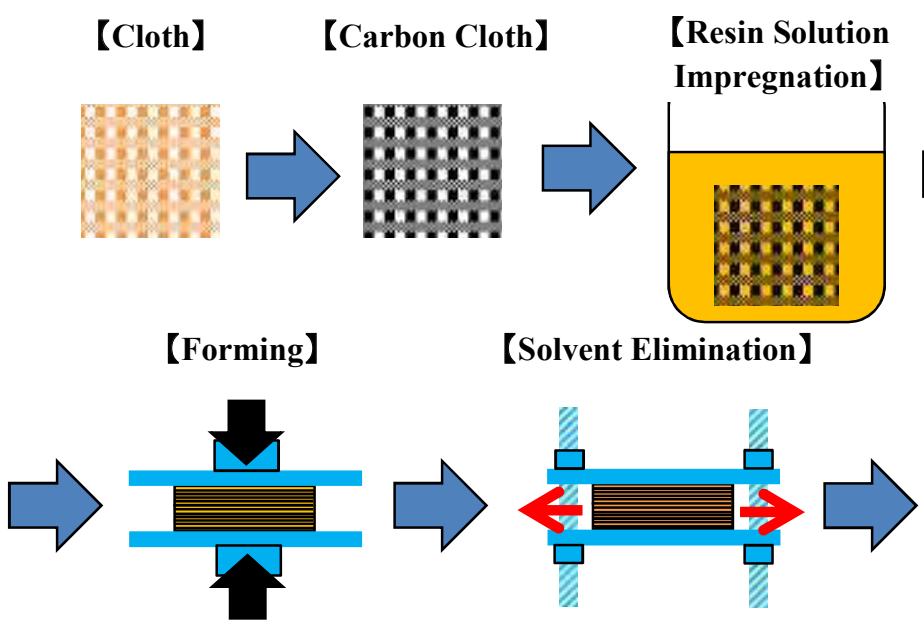

【Solvent Elimination】

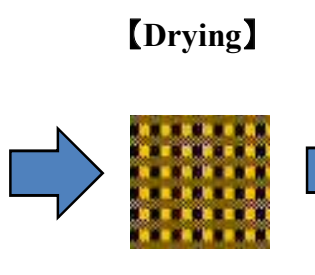

【Curing】

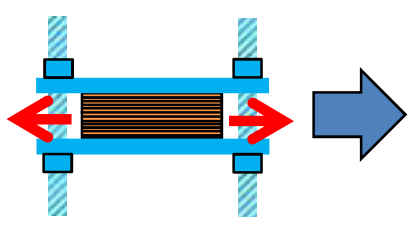

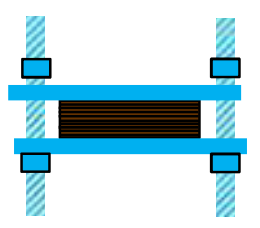

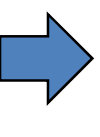

【Lamination Layer】

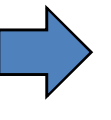

【Machining】

Fig. 4. The manufacturing flow of MD-CFRP. 
maintain the VF and increase the temperature to allow the solvent contained in the prepreg to evaporate and flow out of the system, which leaves numerous open pores.

Actually, the MD-CFRPs constitute a ablator family, the obtained density of which ranges from 0.6 to $1.1 \mathrm{~g} / \mathrm{cm}^{3}$, and the porosity from 10 to $50 \%$ by volume. The level of the density and porosity will be determined depending on the requirements of a re-entry mission.

MD-CFRP billets shown in Fig. 5 are manufactured by hot press method. Various kinds of test coupons are taken from the billets as shown in Fig. 6.

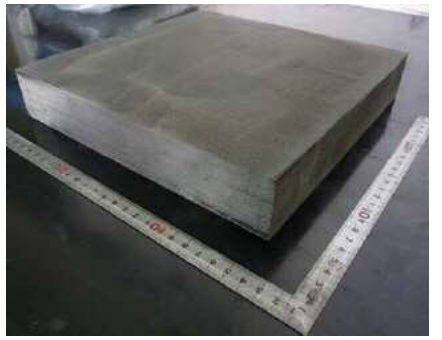

Fig. 5. An example of MD-CFRP billet (Billet Size $=25 \mathrm{~cm} \times 25 \mathrm{~cm} \times$ $50 \mathrm{~mm})$.

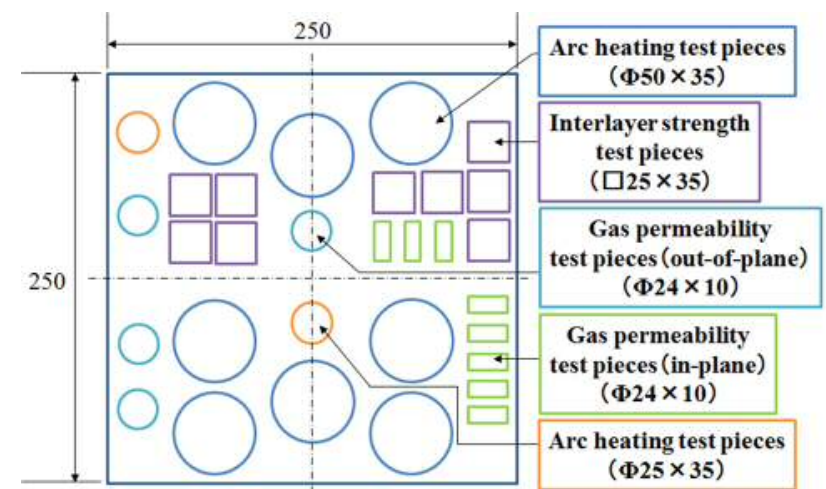

Fig. 6. Schematic of various test coupons taken from a MD-CFRP billet (the unit is shown in $\mathrm{mm}$ ).

\subsection{Confirmation of uniformity of density}

Uniformity of density distribution within the billet is confirmed by measuring the test coupon volume and weight.

The results for all the test coupons that appear in Fig. 6 are shown in Fig. 7, which indicates that the degree of density scattering is within $5 \%$ and the density distribution within a billet is fairly uniform regardless of the bulk density level.

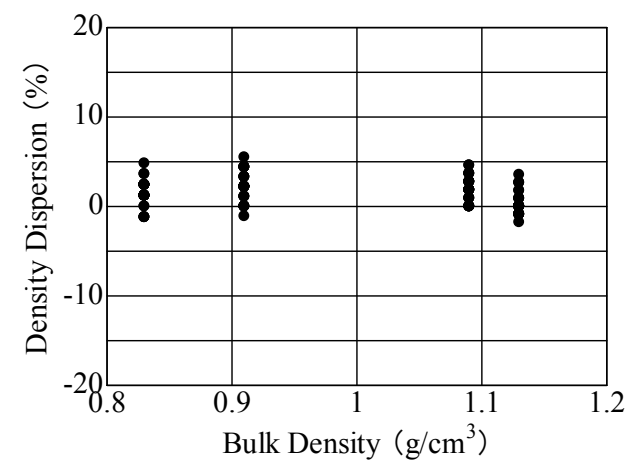

Fig. 7. An example of MD-CFRP density distribution of test coupons within billets (Billet Size $=25 \mathrm{~cm} \times 25 \mathrm{~cm} \times 50 \mathrm{~mm}$ ).

\subsection{Confirmation of porosity}

As indicated by the manufacturing process shown in Fig. 4, most of the pores generated within the resin matrix will be open pores by nature.

The experimental values of porosity within each test coupon are determined by Eq. (1), based on the Archimedes' method using 2-propanol (IPA) for solvent, after drying 3 hours at 80 degree Celsius and vacuuming 1 hour at the pressure of less than $100 \mathrm{~Pa}$. On the other hand, prior to the tests, the values of porosity was calculated by Eq. (2), with the knowledge of the true density of carbon fiber and the resin, as shown below as $\rho_{F}$ and $\rho_{M}$, respectively.

$$
\begin{gathered}
V_{P, E X P}=\frac{\left(W_{\text {sat }}-W_{\text {dry }}\right)}{\left(W_{\text {sat }}-W_{\text {sub }}\right)} \\
V_{P, C A L}=1-V_{F}-V_{M} \\
V_{F}=\frac{W_{c l o t h} / \rho_{F}}{V_{c f r p}} \\
V_{M}=\frac{\left(W_{c f r p}-W_{\text {cloth }}\right) / \rho_{M}}{V_{c f r p}}
\end{gathered}
$$

The results are shown in Fig. 8, which shows that the calculated values of porosity by the above equations successfully reproduce the experimental values.

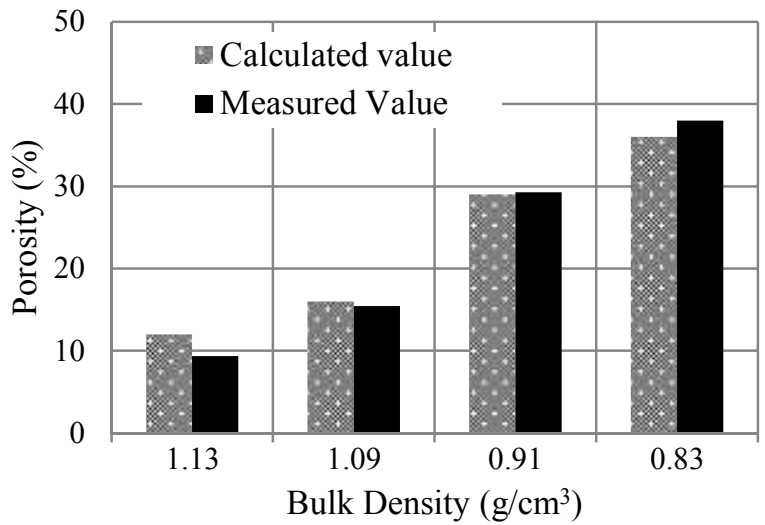

Fig. 8. Comparison of the measured and the calculated porosity of MD-CFRP.

\subsection{Confirmation of gas permeability}

As described in the previous section, the phenolic resin matrix in the MD-CFRP intentionally contains well-controlled amount of voids, which will make the density of MD-CFRP lower and the gas permeability higher.

Gas permeability of the MD-CFRP at room temperature is calculated by Eqs. (5)-(8), based on the experimental values of gas $\left(\mathrm{N}_{2}\right.$ gas) flow rate, operating pressure and the size of the test coupons.

$$
\begin{gathered}
-\frac{\partial P}{\partial x}=\frac{\mu_{G}}{K_{G}} v_{G}=\frac{\mu_{G}}{K_{G}} \frac{\dot{m}_{G}}{\rho_{G}} \\
\dot{m}_{G}=\rho_{G} v_{G} \\
\dot{m}_{G} A=V \dot{\rho}_{G} \\
K_{G}=\frac{\mu_{G}(\dot{V} / A)}{(-\partial P / \partial x)}
\end{gathered}
$$

Test results for gas permeability in the across-the-ply direction are shown in Fig. 9, with the HD-CFRP data shown for comparison. The HD-CFRP test coupons range from 
pristine state to fully charred state, depending on the heat treatment temperature and its duration time. We can find that the gas permeability of the MD-CFRP increases with porosity and on the whole exceeds the one of fully-charred HD-CFRP as expected. We believe that this high porosity of MD-CFRP contributes to avoiding delamination as shown later.

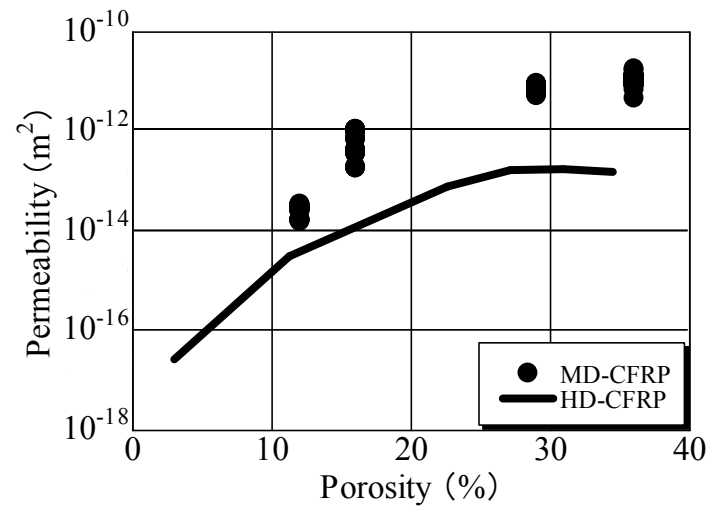

Fig. 9. Comparison of gas permeability data in the across-the-ply direction between MD-CFRP and HD-CFRP.

\section{Aerothermal Response of MD-CFRP}

\subsection{Arc jet heating tests}

Because of its low density characteristics, the recession rates of the MD-CFRP by chemical reaction on the heated surface were predicted to be inferior to the HD-CFRP to some extent. Therefore, the aerothermal response of MD-CFRP is investigated using the $1 \mathrm{MW}$ arc jet facility of JAXA/ISAS. Its operating conditions are shown in Table 1 and the test conditions for MD-CFRP, which are the same conditions as HD-CFRP, are summarized in Table 2. The maximum heat flux is set as $12.6 \mathrm{MW} / \mathrm{m}^{2}$, considering both the facility's limitation and the expected maximum convective heat flux during reentry of the said future missions. All of the test coupons are taken from the $25 \mathrm{~cm} \times 25 \mathrm{~cm} \times 50 \mathrm{~mm}$ sized large billets (void content ranging from 10 to $40 \%$ by volume). The schematic of the test specimen is shown in Fig. 10. In this figure, we notice that as both the top surface and the 10 mm-long side surface from the top surface are directly exposed to the high enthalpy arc jet flow, the measured surface recession rates will be influenced by the effect of side surface heating to some extent. Also it is noted that the side surface heat flux is generally estimated less than $10 \%$ of the top surface heat flux and the exposed surface areas are almost equal between them. Therefore, the measured recession rates based around the center of the top surface will be dominantly determined by the top surface heating conditions. The depth direction of the specimen is intentionally set equal to the cross-ply direction to show that MD-CFRP is free of delamination, because it is the most likely test configuration for delamination
Table 1. Operation conditions of Arc Jet Test Facility at JAXA/ISAS. ${ }^{4}$

\begin{tabular}{ll}
\hline Items & Values \\
\hline Operating Electric Current & $300-700 \mathrm{~A}$ \\
Operating Voltage & Max 2000 VDC \\
Maximum Power & $1 \mathrm{MW}$ \\
Mass Flow Rate & $10-30 \mathrm{~g} / \mathrm{s}$ \\
Enthalpy & $3-20 \mathrm{MJ} / \mathrm{kg}$ \\
Dynamic Pressure & $0.05-0.7 \mathrm{~kg} / \mathrm{cm}^{2}$ \\
\hline
\end{tabular}

Table 2. Test conditions for Arc Jet Tests at JAXA/ISAS.

\begin{tabular}{|c|c|c|c|c|c|c|c|}
\hline \multirow{2}{*}{\multicolumn{2}{|c|}{$\begin{array}{l}\text { Items } \\
\text { Heat Flux }\left(\mathrm{MW} / \mathrm{m}^{2}\right)\end{array}$}} & \multicolumn{6}{|c|}{ Values } \\
\hline & & 1.2 & 3.4 & 3.4 & 5.4 & 5.4 & 12.6 \\
\hline \multicolumn{2}{|l|}{ Gas } & Air & Air & $\mathrm{N}_{2}$ & Air & $\mathrm{N}_{2}$ & Air \\
\hline \multicolumn{2}{|c|}{ Enthalpy (MJ/kg) } & 13 & 13 & 15 & 13 & 15 & 13 \\
\hline \multicolumn{2}{|c|}{ Impact Pressure $(\mathrm{kPa})$} & 5 & 12 & 12 & 21 & 21 & 46 \\
\hline \multicolumn{2}{|c|}{ Duration Time (s) } & 30 & 30 & 30 & 30 & 30 & 30 \\
\hline \multicolumn{2}{|c|}{ Specimen Dia. (mm) } & 50 & 50 & 50 & 50 & 50 & 25 \\
\hline Bulk & $1.13 / 12$ & - & $\bigcirc$ & $\bigcirc$ & $\bigcirc$ & $\bigcirc$ & - \\
\hline Density & $1.09 / 16$ & $\bigcirc$ & $\bigcirc$ & $\bigcirc$ & $\bigcirc$ & $\bigcirc$ & $\bigcirc$ \\
\hline$\left(\mathrm{g} / \mathrm{cm}^{3}\right)$ & $1.01 / 20$ & - & $\bigcirc$ & $\bigcirc$ & $\bigcirc$ & $\bigcirc$ & $\bigcirc$ \\
\hline /Porosity & $0.91 / 29$ & $\bigcirc$ & $\bigcirc$ & $\bigcirc$ & $\bigcirc$ & $\bigcirc$ & $\bigcirc$ \\
\hline \multirow[t]{2}{*}{$(\%)$} & $0.83 / 36$ & $\bigcirc$ & $\bigcirc$ & $\bigcirc$ & $\bigcirc$ & $\bigcirc$ & $\bigcirc$ \\
\hline & $0.59 / 54$ & - & - & - & - & - & $\bigcirc$ \\
\hline
\end{tabular}

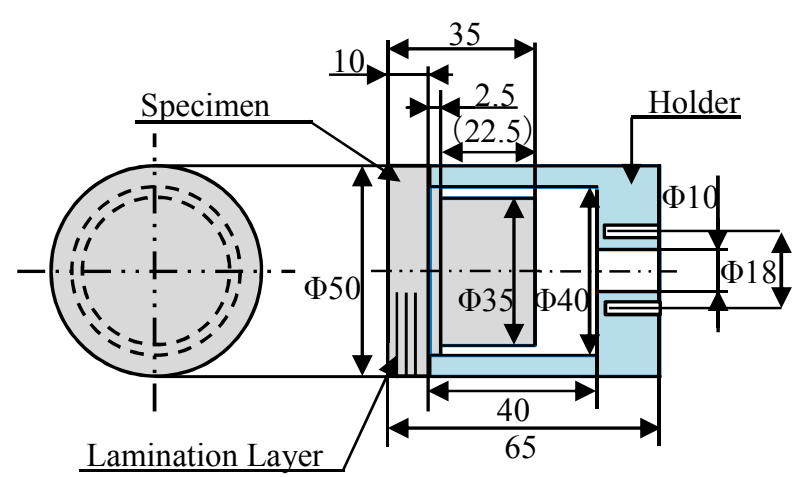

Fig. 10. Schematic of MD-CFRP specimen for arc jet tests (The unit is shown in $\mathrm{mm})$.

The shape of each test coupon (height distribution on the heated surface) is measured by laser 3D measurement system (see Fig. 11) at JAXA/ISAS both before and after the arc jet tests. An example of photograph during arc jet test is shown in Fig. 12. The surface temperature during the tests is measured by monochromatic radiation thermometer (Micron M-90 Vx) at the wavelength of $600 \mathrm{~nm}$. The cold wall heat flux is measured by a Gardon Gauge. The measurement of both surface temperature and heat flux is targeted on the center of the heated surface of the specimen. Therefore, the surface recession is evaluated based on the measured height change data at the center of specimens as shown in Eq. (9), assuming for simplicity the rate is constant during the heating time.

$$
\mathrm{R}=\left(L_{0}-L_{f}\right) / \Delta \mathrm{t}
$$




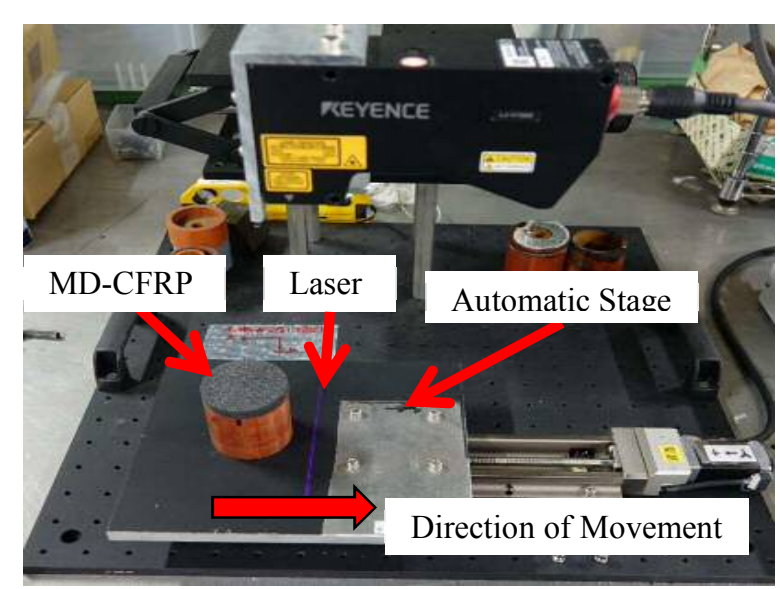

Fig. 11. Photograph of laser 3D measurement system at JAXA/ISAS.

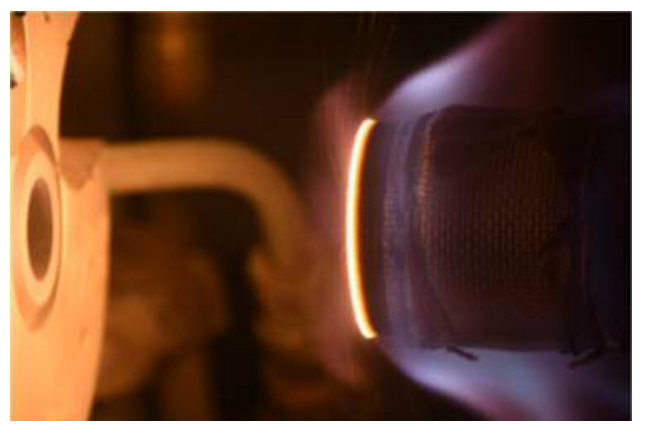

Fig. 12. A Photograph of MD-CFRP during arc jet tests ( $\rho 0.83$ specimen at $5.4 \mathrm{MW} / \mathrm{m}^{2}$ under air flow).

Examples of measurement of the surface temperature are shown in Fig. 13, which shows the specimens are exposed to the surface temperature ranging from 1600 to 3000 degree Celsius. The appearance after the tests is shown in Fig. 14, which indicates that there are no sign of delamination over considerable wide range of heat flux despite the fact that the heat flux comes in perpendicular to the lamination layers.
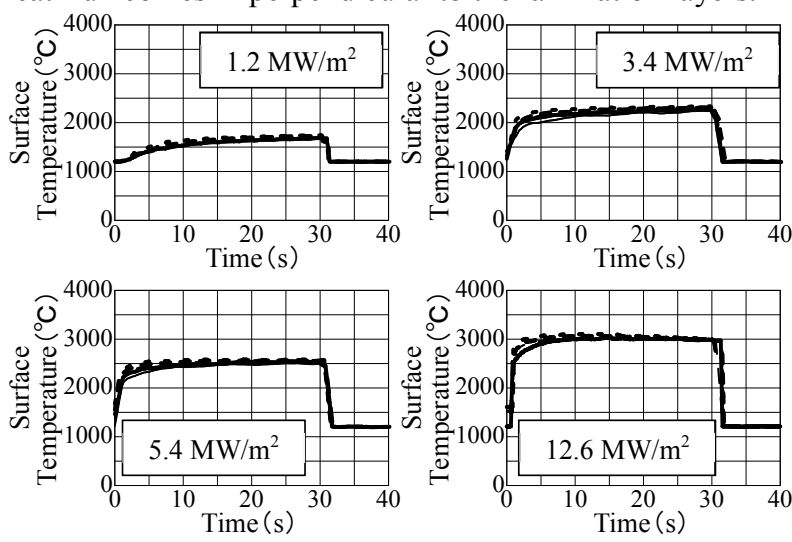

Fig. 13. Surface temperature of MD-CFRP during arc jet tests.

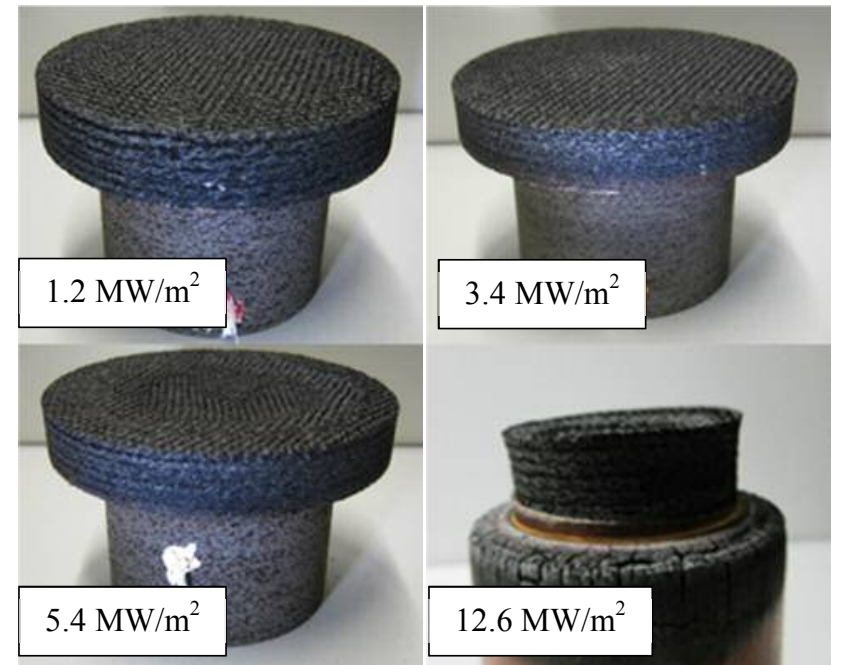

Fig. 14. Appearance of MD-CFRP test specimens after JAXA/ISAS arc jest tests.

\subsection{Surface recession characteristics}

\subsubsection{Raw data of surface recession}

The raw data of surface recession are shown in Fig. 15, where the experimental values of a typical HD-CFRP are shown for comparison. It is known that the recession characteristics of PICA (Phenolic Impregnated Carbon Ablator) can be expressed as functions of heat flux and pitot pressure, or impact pressure, on the specimens. According to Ref. 5), the recession rate of PICA can be estimated by the correlation line shown in Fig. 16, using the heat flux values specified in the unit of $\mathrm{W} / \mathrm{cm}^{2}$ and impact pressure values specified in the unit of $\mathrm{kPa}$, respectively. As PICA has never been imported to Japan, the recession rates of PICA at JAXA/ISAS arc jet facility are calculated by Fig. 16, using the values of heat flux and impact pressure shown in Table 2.

From Fig. 15, we can notice that surface recession rates of MD-CFRP are almost zero under an inert gas $\left(\mathrm{N}_{2}\right)$ atmosphere regardless of MD-CFRP's density level, which imply MD-CFRPs do survive the dynamic pressure. And the experimental recession rates decrease linearly with density level from PICA to MD-CFRP to HD-CFRP. As a matter of fact, although MD-CFRP would be a lighter alternative of HD-CFRP, the recession rate of MD-CFRP would be larger compared to HD-CFRP. Therefore, the endorsement of MD-CFRP would be thought as a matter of system design policy.

These results imply that the main mechanism of surface recession of MD-CFRP seems to be caused by the surface oxidation reaction, which will be discussed quantitatively in the next section.

Apropos, the minus recession rate at $1.2 \mathrm{MW} / \mathrm{m}^{2}$ indicate that the specimen swells. As a matter of fact, the effective recession rate calculated by Eq. (9) consists of two factors, such as the surface recession due to oxidation reaction between $\mathrm{C}(\mathrm{s})$ and $\mathrm{O}(\mathrm{g})$ and also thermal expansion due likely to the internally built-up pressure during pyrolysis reaction of the resin. This internal pressure build-up mechanism is explained in Ref. 7). 

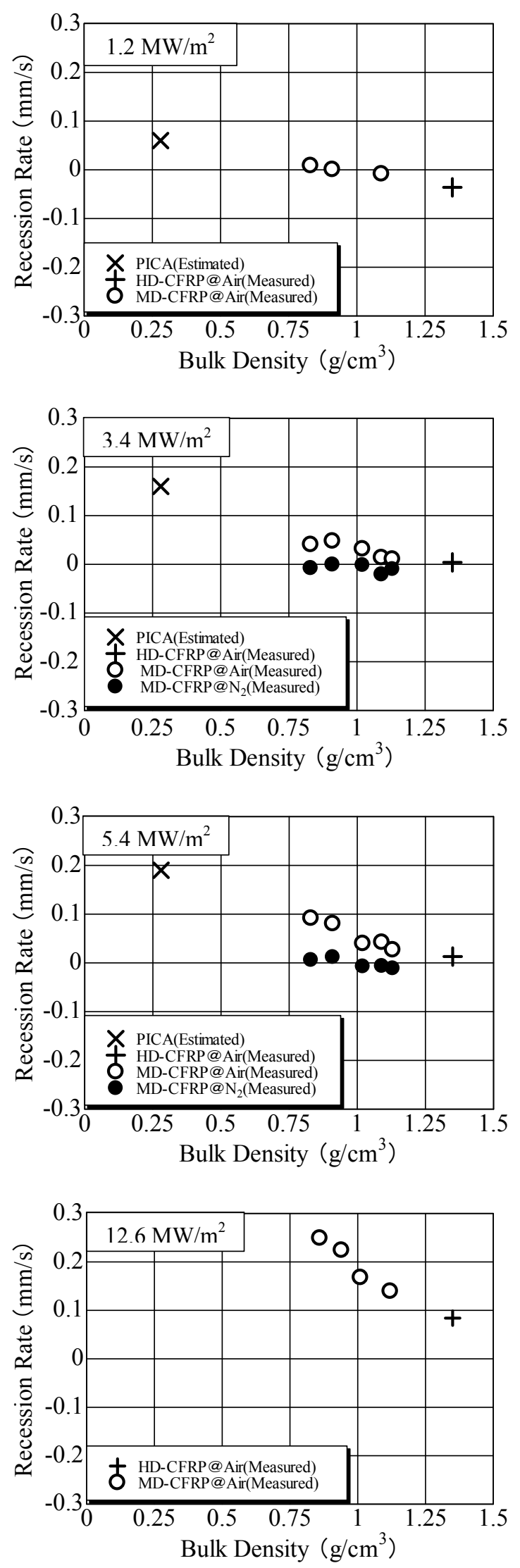

Fig. 15. Recession rate data of MD-CFRP at various heating conditions.

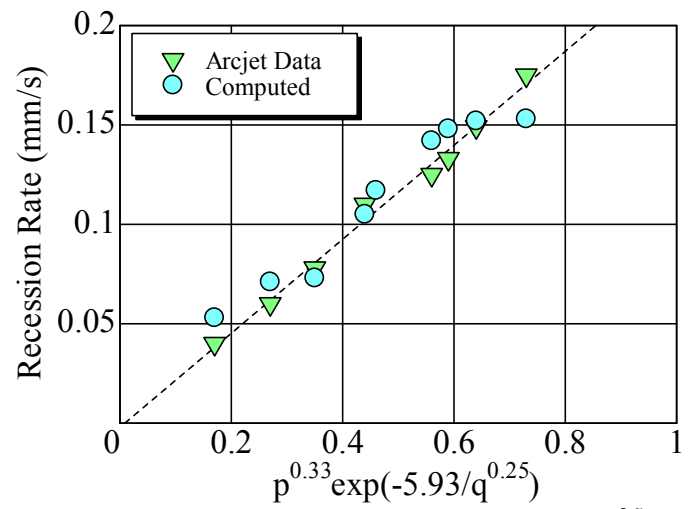

Fig. 16. Empirical recession rate model of PICA. ${ }^{5,6)}$

\subsubsection{Normalized recession data}

As apparent in the definition of the recession rates by Eq. (9), only surface recession is treated in this paper. Volume recession will not be treated here. Therefore, $\dot{m}_{a b}$ that appears later in this section only covers the surface recession due to the oxidation reaction on the heated surface.

In this section, surface recession characteristics of MD-CFRP are evaluated by normalized ablation rate B'c as shown in Eqs. (10)-(17). ${ }^{8)}$ The schematic for surface reaction is shown in Fig. 17.

The following experimental values are used for the B'c evaluation.

MD-CFRP test specimen:

(1) recession rate $(\mathrm{R})$

(2) char density $\left(\rho_{c}\right)$

(3) surface temperature $\left(T_{w}\right)$

Arc Jet Facility:

(1) cold wall heat flux $\left(q_{c w}\right)$

(2) arc jet flow enthalpy $\left(h_{r}\right)$

Here, char density is estimated by Eq. (16), where the value of VF is calculated by counting the number of carbon-cloth layers contained in the char layer of the specimen's cross section by microscope after the heating test and also the value of VM is calculated by assuming the carbon yield for phenolic resin is $50 \%$ by weight. An example of the cross section view of a specimen by microscope is shown in Fig. 18.

Using this estimated value of char density, surface mass loss rate is evaluated by Eq. (15).

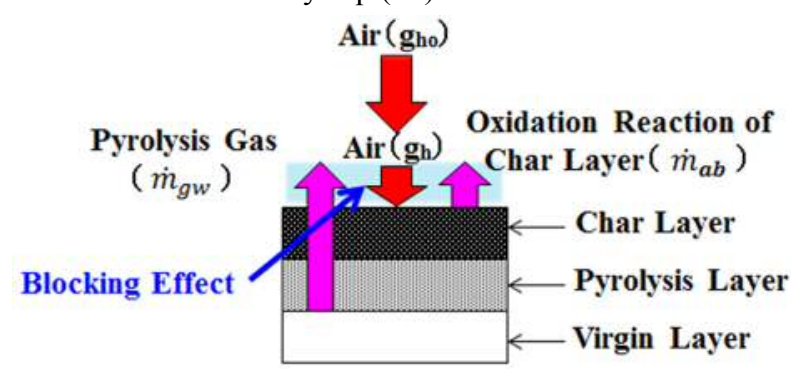

Fig. 17. Schematic of surface chemical reactions

$$
\begin{gathered}
\dot{q}_{c o n v}=g_{h}\left(h_{r}-h_{w}\right) \\
\dot{q}_{c w}=g_{h o} h_{r} \\
g_{h}=g_{h o} \varphi_{\text {blow }}
\end{gathered}
$$




$$
\begin{gathered}
\varphi_{\text {blow }}=\frac{a B_{O}^{\prime}}{\exp \left(a B_{O}^{\prime}\right)-1} \\
B_{O}^{\prime}=\frac{\dot{m}_{a b}+\dot{m}_{g w}}{g_{h o}} \\
\dot{m}_{a b}=\rho_{c} R \\
\rho_{c}=\left(\rho_{o} W_{F}+\rho_{O} W_{M} \times 0.5\right) \times \frac{l_{c o}}{l_{c}} \\
B_{c}^{\prime}=\frac{\dot{m}_{a b}}{g_{h}}=\frac{h_{r}}{\dot{q}_{c w}} \dot{m}_{a b} \times \frac{1}{\varphi_{\text {blow }}}
\end{gathered}
$$

In the present case, $\varphi_{\text {blow }}$ is almost 1 . The normalized recession rates B'cs for MD-CFRP are shown in Fig. 19. From the figure, we can find that the obtained data for MD-CFRP follow the trend of pure carbon recession characteristics, as is the case with those of HD-CFRP, which are shown in Ref. 9). That is to say, the surface recession of the carbonaceous ablators may be approximated by carbon ablation model fairly well. However, we notice that the obtained data for MD-CFRP are slightly lower than the B'c curve. For the moment, we believe that this slight difference traces back to the contribution of the generated decomposed gases inside MD-CFRP to the surface chemical reaction between air and the char carbon.
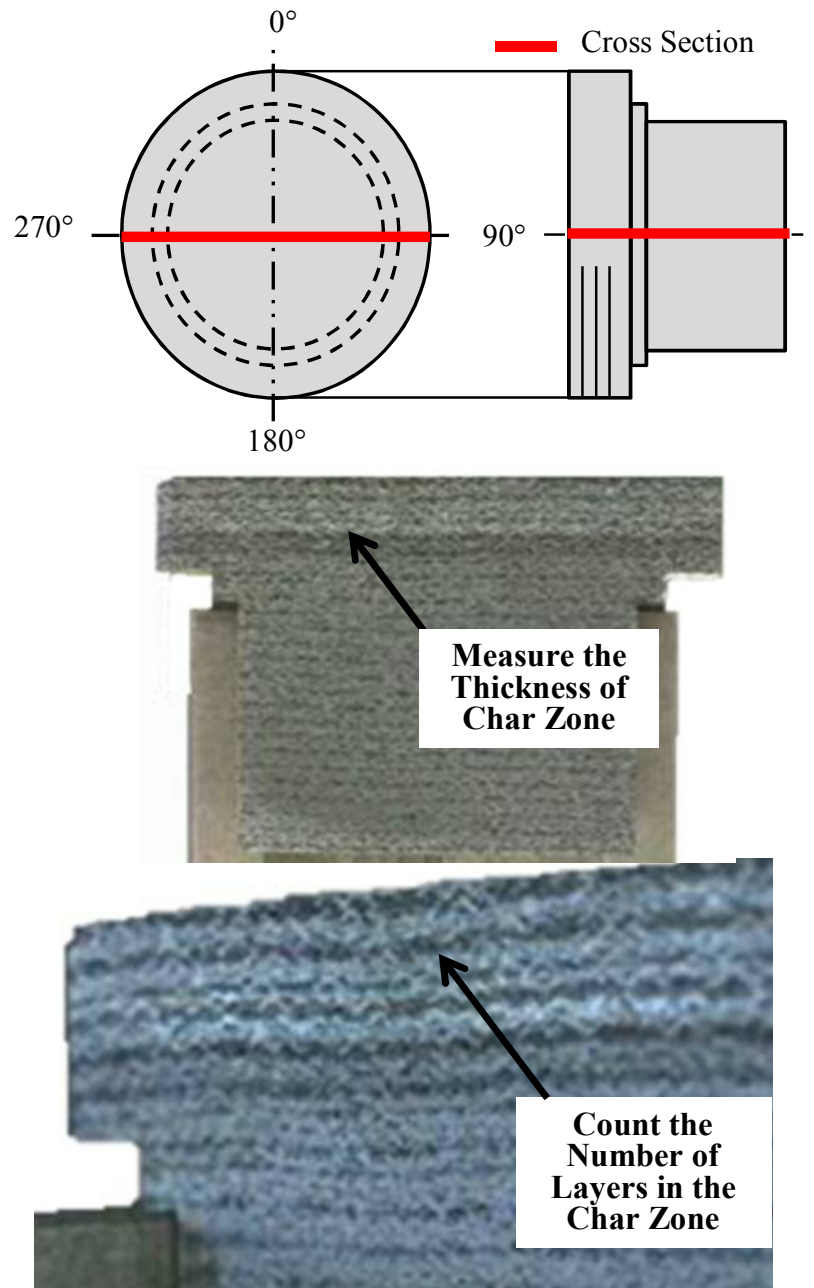

Fig. 18. An example of the cross-section view of a specimen by microscope after the arc jet test ( $\rho 0.83$ specimen at $3.4 \mathrm{MW} / \mathrm{m}^{2}$ under air flow).

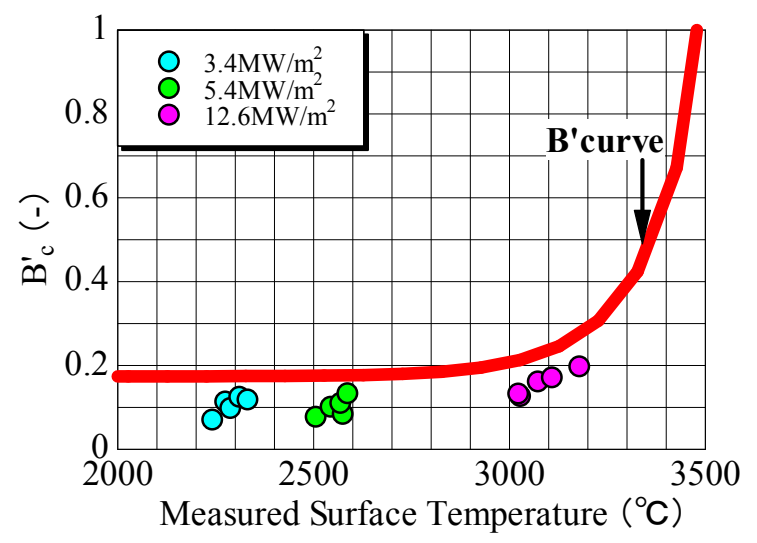

Fig. 19. Calculated B'c data for MD-CFRP.

\section{Manufacturing Large Size Parts for Heat Shield}

The estimated time history of the aerodynamic heating of the HAYABUSA capsule during the Earth re-entry is shown in Fig. $20 .^{2)}$ In this figure, $q_{t o t}$ is designated as the maximum heat flux on the stagnation point, which amounts to the sum of the convective heat flux $\left(q_{c}\right)$ and the radiative heat flux $\left(q_{r}\right)$. The approximate values of $q_{t o t}, q_{c}$ and $q_{r}$ are estimated as $14 \mathrm{MW} / \mathrm{m}^{2}, 12 \mathrm{MW} / \mathrm{m}^{2}, 2 \mathrm{MW} / \mathrm{m}^{2}$, respectively. Among them, the value of the $q_{c}$ is directly related to the oxygen mass flux and it influences the surface recession rate as a result.

Currently, the value of the $q_{c}$ of the future sample return capsule as shown in Fig. 2, is being planned to have the same $q_{c}$ level as the HAYABUSA. Therefore, MD-CFRP is estimated to survive the aerodynamic environment.

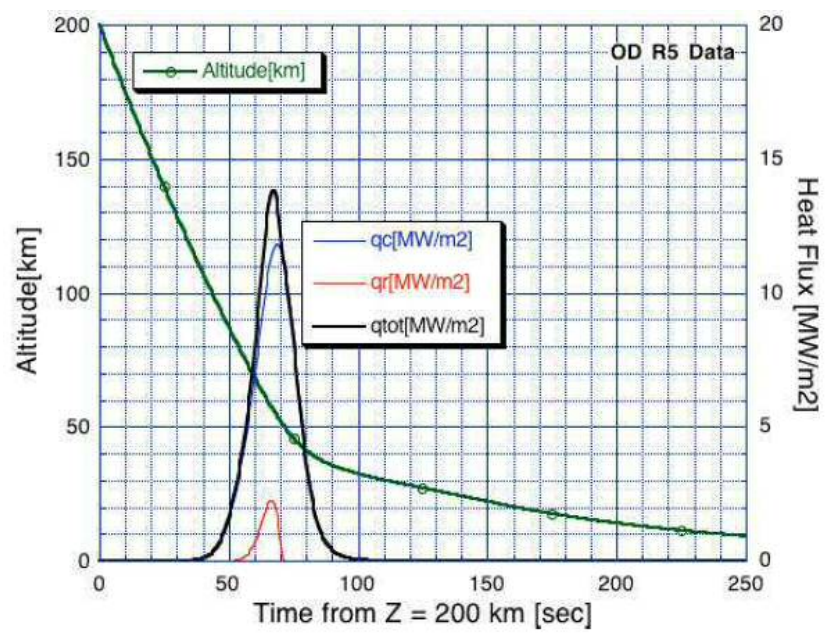

Fig. 20. Estimated time history of the HAYABUSA capsule stagnation point heating environment during the Earth re-entry. ${ }^{2)}$

MD-CFRP billets previously shown in Fig. 5 (a rectangular of $25 \mathrm{~cm} \times 25 \mathrm{~cm} \times 50 \mathrm{~mm}$ in size) are manufactured by hot press method because of its simplicity of shape.

However, the actual shape of the reentry capsule heat shield is rather complex. We believe that it is important to show that the actual shape of the reentry capsule heat shield made of MD-CFRP can be manufactured. Therefore, as a next step, we move on to the trial production of the forward section of the HAYABUSA heat shield shown in Fig. 21 by Autoclave 
method in order to demonstrate the feasibility of fabrication of a large body with complex and curved surfaces.

In manufacturing the heat shield, MD-CFRP density level is adjusted as approximately $0.8 \mathrm{~g} / \mathrm{cm}^{3}$ and the shape is simplified as shown in Fig. 22. The thickness is set equal to $25 \mathrm{~mm}$ all over.

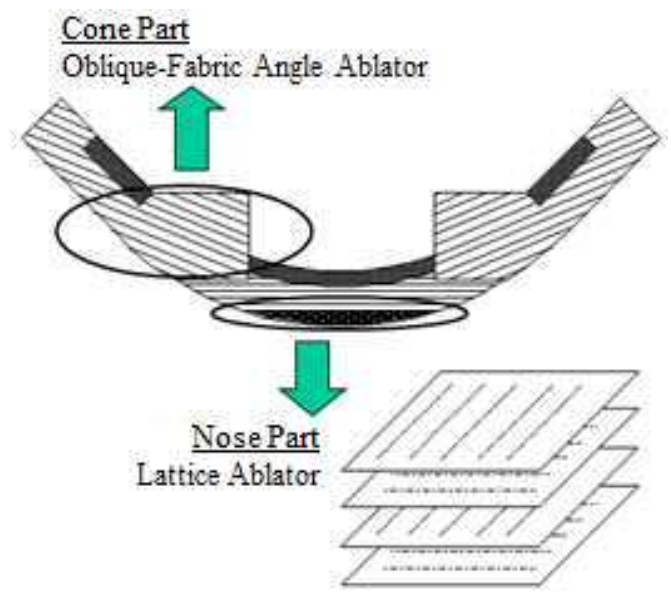

Fig. 21. Schematic of the forward section of the HAYABUSA heat shield. $^{10)}$

We manufactured the cone part and the nose part separately and combined them by an epoxy adhesive. A photograph of the manufactured heat shield model is shown in Fig. 23. We confirmed by 3-dimensional measuring devices (Mitutoyo CRYSTA-Apex C9106) at Tokyo Metropolitan Industrial Technology Research Institute that the model is successfully shaped as designed.

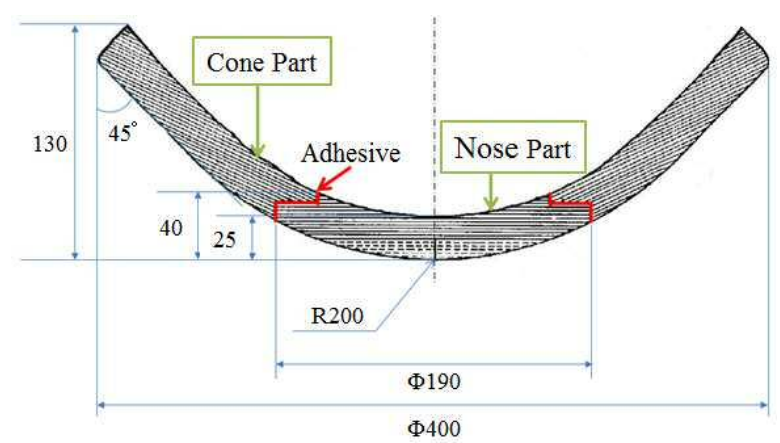

Fig. 22. Schematic of the newly manufactured heat shield model.

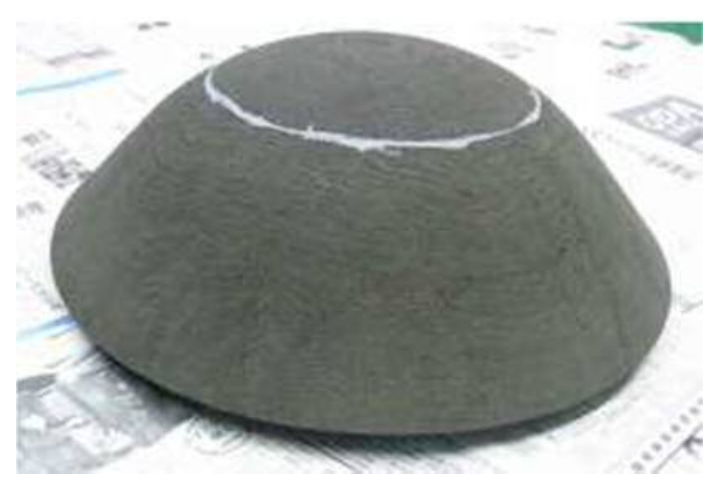

Fig. 23. Photograph of the manufactured heat shield model.

\section{Conclusion}

The development of MD-CFRP is currently underway to prove that it is a promising candidate for heat shield materials for future re-entry capsules.

First, we manufactured medium-sized billets $(25 \mathrm{~cm} \times 25 \mathrm{~cm}$ $\times 6 \mathrm{~cm}$ ) by hot press method in order to clarify the basic characteristics of MD-CFRP. Here, the porosity level is targeted around the same level as the porosity of HD-CFRP's fully charred layer to secure sufficient gas permeability to avoid delamination. So far, the development of MD-CFRP can be judge successful in terms of good uniformity of density within a billet, good surface recession characteristics from 1 to $12 \mathrm{MW} / \mathrm{m}^{2}$, and no sign of delamination, indicating that the concept of MD-CFRP is effective.

Secondly, we moved on to the trial production of the forward section of the HAYABUSA heat shield by autoclave method to demonstrate the feasibility of fabrication of a large body with complex and curved surfaces. The model was successfully shaped as designed.

However, the development of MD-CFRP is still in progress toward significant reduction in the TPS mass fraction.

\section{Acknowledgments}

The authors would like to acknowledge the contribution of Mr. Nagai, Mr. Yoshida and Dr. Shimoda of JAXA/ISAS for successfully conducting a series of Arc Jet experiments on schedule. And we would like to give special thanks to $\mathrm{Mr}$. Araya and Mr. Fukuda of Tokyo University of Science for corroborative works.

\section{References}

1) Laub, B. and Venkatapathy, E.: Thermal Protection System Technology and Facility Needs for Demanding Future Planetary Missions, International Workshop on Planetary Probe Atmospheric Entry and Descent Trajectory Analysis and Science, 2003.

2) Yamada, T., Inatani, Y., and Tan'no, H.: Post-Flight Analysis of the Recovered Heatshield and Results from Airborne Observation, Proceedings of the 63rd International Astronautical Congress, IAC-12,C2,1,9,x15178, 2014.

3) Yano, H., Mori, O., Matsuura, S., Funase, R., Nakamura, R., Yoshida, F., et al.: The Solar Power Sail Mission to Jupiter Trojans, The 10th IAA International Conference on Low Cost Planetary Missions, 2013.

4) Shimoda, T., Yamada, K., and Takahashi, Y.: Characterization of JAXA/ISASA Arc Wind Test Facility, Proceedings of the 46th Fluid Dynamics Conference/32nd Aerospace Numerical Simulation Symposium, JAXA-SP-14-020, 2014, pp. 13-15 (in Japanese).

5) Hwang, H. H., Driver, D. M., Wright, M. J., and Beck, R. A. S.: Race towards Launch: Qualifying the Mars Science Laboratory Heat Shield in under Ten Months, World Journal of Engineering, Issue Supplement (2009), pp.383-384.

6) Milos, F. S. and Chen, Y-K: Ablation and Thermal Response Property Model Validation for Phenolic Impregnated Carbon Ablators, AIAA Paper 2009-0262, 2009.

7) Konayagi, J., Fukuda, Y., Yoneyama, S., Hirai, K., Yoshimura, A., Aoki, T., and Ogasawara, T.: Local Out-of-Plane Deformation of CFRP Ablator Subjected to Rapid Heating, J. Japan Society for Composite Materials, 42 (2016), pp.146-152 (in Japanese). 
Trans. JSASS Aerospace Tech. Japan Vol. 17, No. 3 (2019)

8) Potts, R. L: Hybrid Integral/Quasi-Steady Solution of Charring Ablation, AIAA Paper 90-1677, 1990.

9) Hirai, K., Niikura, K., Nogi, S., and Shimada, T.: Numerical Simulations of Charring Ablation for the Heatshields on Super-Orbital Reentry Capsule, Proceedings of the $21 \mathrm{st}$
International Symposium on Space Technology and Science, ISTS-98-d-08, 1998.

10) Inatani, Y., Ishii, N., Yamada, T., and Hiraki, K.: Aerodynamics and Aerothermodynamics of Asteroid Sample Return Capsule, Nagare, 24 (2005), pp .297-305 (in Japanese). 